\title{
FLORÍSTICA E ESTRUTURA DA COMUNIDADE ARBÓREA DE UM FRAGMENTO FLORESTAL EM LUMINÁRIAS, MG ${ }^{1}$
}

\author{
Luciene Alves Rodrigues ${ }^{2}$ \\ Douglas Antônio de Carvalho ${ }^{3}$ \\ Ary Teixeira de Oliveira Filho ${ }^{4}$ \\ Rejane Tavares Botrel ${ }^{4}$ \\ Érica Aparecida da Silva ${ }^{3}$
}

Recebido em 10/07/2001. Aceito em 17/05/2002

\begin{abstract}
RESUMO - (Florística e estrutura da comunidade arbórea de um fragmento florestal em Luminárias, MG). O objetivo deste trabalho foi analisar a composição florística e estrutural da comunidade arbórea de uma floresta em Luminárias, MG. O local de estudo é conhecido como Mata do Galego, possui cerca de 77 ha e está localizado a $21^{\circ} 29^{\prime} \mathrm{S}$ e $44^{\circ} 55^{\prime} \mathrm{W}$, às margens do rio Ingaí. A amostragem florística foi realizada em parcelas e também em caminhadas pela floresta. Todo o material coletado foi identificado e incorporado ao Herbário ESAL, da Universidade Federal de Lavras. O levantamento estrutural foi realizado por meio de amostragem sistemática, em 32 parcelas de $20 \times 20 \mathrm{~m}$, distribuídas em três transeções, da margem do rio até a borda da mata. Nas parcelas, foram amostrados todos os indivíduos arbóreos, vivos, com circunferência à altura do peito $(\mathrm{CAP}) \geq 15,5 \mathrm{~cm}$. As variáveis químicas e físicas do solo foram obtidas das análises de amostras superficiais de solo $(0-20 \mathrm{~cm})$ de cada parcela. No levantamento florístico foram amostradas 201 espécies, 129 gêneros e 57 famílias. As famílias com maior riqueza foram Myrtaceae, Lauraceae, Fabaceae Faboideae, Rubiaceae, Euphorbiaceae e Fabaceae Mimosoideae. No levantamento estrutural foram amostrados 2343 indivíduos de 159 espécies, 104 gêneros e 50 famílias. As espécies mais abundantes foram Casearia sylvestris, Lithraea molleoides, Machaerium stipitatum, Faramea cyanea, Diospyros inconstans e Copaifera langsdorffii. A Mata do Galego apresentou alta diversidade de espécies $\left(\mathrm{H}^{\prime}=\right.$ 4,23 nat/indivíduo) e alta equabilidade $\left(\mathrm{J}^{\prime}=0,83\right)$. A alta diversidade de espécies pode estar relacionada à influência de formações vegetais próximas e aos diferentes microhabitats proporcionados pela topografia, variações na fertilidade e umidade do solo.
\end{abstract}

Palavras-chave - florística, estrutura, floresta estacional semidecidual

\footnotetext{
1 Parte da Dissertação de Mestrado da primeira autora. Este trabalho integra o Subprojeto Estratégias para conservação e manejo da biodiversidade em fragmentos de florestas semidecíduas executado pela EMBRAPA Recursos Genéticos, a Universidade Federal de Lavras (UFLA) e Universidade de Brasília (UnB) e integrante do Projeto de Conservação e Utilização Sustentável da Diversidade Biológica Brasileira (PROBIO) supervisionado pelo Ministério do Meio Ambiente (MMA), gerido pelo Conselho Nacional de Desenvolvimento Científico e Tecnológico (CNPq) e apresentado pelo governo brasileiro ao GEF/BIRD

2 R. Prefeito Antônio Cândido, 41, CEP 39280-000, Buritizeiro, MG, Brasil

3 Departamento de Biologia, Universidade Federal de Lavras, C. Postal 37, CEP 37200-000, Lavras, MG, Brasil (douglasc@ufla.br)

${ }_{4}$ Departamento de Ciências Florestais, Universidade Federal de Lavras, CEP 37200-000, Lavras, MG, Brasil (aryfilho@ufla.br)
} 


\begin{abstract}
Floristic composition and structure of the tree layer of a forest fragment in Luminárias Municipality, Minas Gerais State). The aim of this study was to analyze the floristic composition and structure of the tree layer of a forest fragment in the municipality of Luminárias, Minas Gerais State, southeastern Brazil. The forest fragment is locally known as Mata do Galego, has an area of c. 77 ha, and is located on the banks of the Ingaí River $\left(21^{\circ} 29^{\prime} \mathrm{S}, 44^{\circ} 55^{\prime} \mathrm{W}\right)$. The flora was sampled out both in the stdy plots and in random collections throughout the fragment. Plant specimen vouchers are deposited in the ESAL Herbarium, Federal University of Lavras. The structural survey used a systematic design with 32 sample plots $(20 \times 20 \mathrm{~m})$ distributed on three transects which extended from the river margin to the forest edge. In these plots, all living trees, with circumference at breast height $(\mathrm{cbh}) \geq 15.5 \mathrm{~cm}$ were recorded. Soil chemical and physical variables were obtained from the analysis of samples of the topsoil $(0-20 \mathrm{~cm})$ taken at the center of each plot. The floristic survey totaled 201 species belonging to 129 genera and 57 families. The families with the highest number of species were Myrtaceae, Lauraceae, Fabaceae Faboideae, Rubiaceae, Euphorbiaceae, and Fabaceae Mimosoideae. The structural survey recorded 2343 individuals belonging to 159 species, 104 genera, and 50 families. The most abundant species were Casearia sylvestris, Lithraea molleoides, Machaerium stipitatum, Faramea cyanea, Diospyros inconstans, and Copaifera langsdorffii. The Mata do Galego had a relatively high species diversity $\left(\mathrm{H}^{\prime}=4.23\right.$ nat/indivíduo $)$ and evenness $\left(\mathrm{J}^{\prime}=0.83\right)$ and may be related to the influence of adjacent vegetation formations and to the different microhabitats present within the forest, determined by several factors, such as canopy gaps, topography, variation in soil fertility and moisture.
\end{abstract}

Key words - flora, structure, semideciduous florest

\section{Introdução}

Nas últimas décadas, houve considerável avanço nos estudos de comunidades florestais, principalmente por causa de sua importância para a conservação da diversidade biológica. Essa importância se torna cada dia mais acentuada devido ao processo desordenado de ocupação do solo que, nas mais diversas regiões do país, tem transformado formações florestais contínuas em fragmentos. Além disso, geralmente os remanescentes estão localizados em propriedades particulares e estão sujeitos às mais diversas perturbações. Na região Sul de Minas Gerais, os remanescentes vegetais são, na sua maioria, bastante perturbados pelo fogo, pela pecuária extensiva e retirada seletiva de madeira (Oliveira Filho et al. 1994a).

Vários estudos têm mostrado que um dos principais fatores atuando na composição florística e estrutura das florestas é a heterogeneidade ambiental, cujos efeitos podem ser observados mesmo no interior de pequenos fragmentos (Rodrigues et al. 1989; Oliveira Filho et al. 1994a; 1994c; 1994d; 1998, Durigan et al. 2000). Essa heterogeneidade é resultado da diversidade de fatores que interagem nas comunidades e a resposta das espécies a esses fatores faz com que cada local tenha características próprias e características que são comuns a outros locais, possibilitando observar tendências. Essas tendências podem responder algumas perguntas e gerar várias outras, funcionando como força motriz para novos estudos.

A Mata do Galego, fragmento florestal situado no município de Luminárias, MG, estudado no presente trabalho, tem grande importância na preservação da flora e da fauna regionais por estar conectada a outros fragmentos menores, o que permite fluxo de animais dispersores e polinizadores entre fragmentos. O objetivo do presente trabalho foi analisar variações espaciais da composição e estrutura da comunidade arbórea da Mata do Galego.

\section{Material e métodos}

Local de estudo - A área de estudo localiza-se nas Fazendas Barreiro e Morro Grande, município de Luminárias, Minas Gerais, às margens do Rio Ingaí, nas coordenadas $21^{\circ} 29^{\prime} \mathrm{S}$ e $44^{\circ} 55^{\prime} \mathrm{W}$, entre 880 e $1.001 \mathrm{~m}$ de altitude 
(Fig. 1). O fragmento florestal é conhecido localmente por Mata do Galego e possui aproximadamente 77 ha. $\mathrm{O}$ desnível entre a borda da mata, no alto da encosta, até o rio é de $121 \mathrm{~m}$, o que origina um gradiente ambiental e vegetacional, que inclui representações da Floresta Estacional Semidecidual Aluvial e Floresta Estacional Semidecidual Montana, segundo a classificação do IBGE (Veloso et al. 1991).

Segundo informações locais, houve retirada de madeira na Mata do Galego. O desmatamento teve início no final da década de 1930 e nas áreas abertas plantavam-se milho, arroz e feijão, por mais ou menos dois anos. Após este período, a área era abandonada e nova área era desmatada e cultivada. Esses ciclos duraram aproximadamente dez anos. Foi aberta uma estrada dentro da mata, margeando o rio Ingaí, por onde se retirava madeira e se transportava o cascalho retirado do rio. Atualmente, não ocorre exploração de cascalho nem de madeira, mas há entrada de gado de uma das fazendas. Uma das extremidades da floresta tem ligação com remanescentes menores, uma das bordas tem interface com campo de altitude e uma outra com áreas agrícolas.

O clima da região é do tipo $\mathrm{Cwb}$, segundo a classificação de Köppen, com verão úmido e inverno seco. A temperatura média anual, de acordo com dados da Estação Meteorológica de Lavras, é de $19,61^{\circ} \mathrm{C}$, com médias mensais variando entre $16,0^{\circ} \mathrm{C}$ (julho) e $21,8^{\circ} \mathrm{C}$ (janeiro). A precipitação anual média é de $1517 \mathrm{~mm}$ (Oliveira Filho et al. 1994d).

Levantamento e classificação de solos Foram coletadas amostras simples de solo superficial $(0-20 \mathrm{~cm}$ de profundidade) no centro geométrico de cada parcela. As análises químicas e granulométricas foram realizadas no Laboratório de Análise de Solos da Universidade Federal de Lavras, de acordo com métodos recomendados pela EMBRAPA (1979). Os solos foram classificados de acordo com a o
Sistema Brasileiro de Classificação de Solos (EMBRAPA, 1999).

Levantamento florístico - A amostragem florística das espécies arbóreas e arbustivas foi realizada no interior de parcelas durante o levantamento estrutural e também fora das parcelas, em caminhadas pela mata, de janeiro a maio de 2000. Todo o material coletado foi levado para o Herbário ESAL, da Universidade Federal de Lavras (UFLA), herborizado e incorporado. A identificação dos exemplares foi feita por comparação com exsicatas do Herbário ESAL, Herbário do Jardim Botânico do Rio de Janeiro (RB), Instituto de Botânica de São Paulo (SP) e Universidade Estadual de Campinas (UEC), por meio de consultas à literatura e/ou, por especialistas. O sistema de classificação adotado foi o do Angiosperm Philogeny Group (APG) (Judd et al. 1999).

Levantamento estrutural - O levantamento estrutural foi realizado por meio de 32 parcelas de $20 \times 20 \mathrm{~m}$, distribuídas em três transeções, dispostas da margem do rio até a borda da mata, para que se pudesse abranger o gradiente ambiental e vegetacional presumido para a área (Fig. 1C). A amostragem foi sistemática, sendo a primeira parcela estabelecida de forma preferencial. A partir desta, a distância entre as demais parcelas nas transeções foi de $50 \mathrm{~m}$ e a distância média entre transeções foi de $64 \mathrm{~m}$. Foram amostrados todos os indivíduos arbóreos vivos e com circunferência à altura de $1,30 \mathrm{~m}$ do solo $(\mathrm{CAP}) \geq 15,5 \mathrm{~cm}$. Os indivíduos bifurcados foram incluídos na amostragem quando a área basal total dos troncos correspondia ao CAP mínimo adotado neste trabalho. A altura foi estimada visualmente, sempre pelo mesmo membro da equipe, durante todo o levantamento. $\mathrm{O}$ valor da altura correspondeu à distância do solo até o ponto mais alto alcançado pela árvore.

Para descrever a estrutura horizontal da floresta, foram estimados os seguintes parâmetros fitossociológicos: densidade absoluta 
(DA), freqüência absoluta (FA), dominância absoluta (DoA) e valor de importância (VI) (Mueller-Dombois \& Ellenberg 1974). Foram calculados também o índice de diversidade de Shannon (H') e índice de equabilidade de Pielou (J') (Magurran 1988). Para obtenção dos parâmetros e índices, os dados foram processados no software FITOPAC 1 (Shepherd 1994).

\section{Resultados e discussão}

Levantamento e classificação de solos - Os grupos de solos encontrados na área de estudo foram Neossolo Flúvico, Argissolo Vermelho fase média fertilidade, Argissolo Vermelho fase baixa fertilidade e Cambissolo Háplico. Entre esses grupos, apenas o Neossolo Flúvico não foi representado dentro das parcelas. As variáveis alumínio (Al), saturação por alumínio e areia aumentaram ao longo do gradiente Argissolo Vermelho $\rightarrow$ Cambissolo Háplico, que coincide com o aumento da altitude (Tab. 1). Por outro lado, o pH, soma de bases e a relação $\mathrm{Ca}+\mathrm{Mg} / \mathrm{Al}$ diminuíram ao longo deste gradiente. Esses resultados indicam que a topografia provavelmente influenciou nas características químicas e físicas do solo. Os solos da parte mais íngreme da encosta são mais rasos, mais arenosos e, conseqüentemente, mais fortemente drenados, o que ocasionou maior concentração de $\mathrm{Al}$ e baixos níveis de $\mathrm{Ca}+\mathrm{Mg}$.

Levantamento florístico - No levantamento florístico da Mata do Galego foram encontradas 201 espécies, pertencentes a 129 gêneros e 57 famílias (Tab. 2). O número de espécies pode

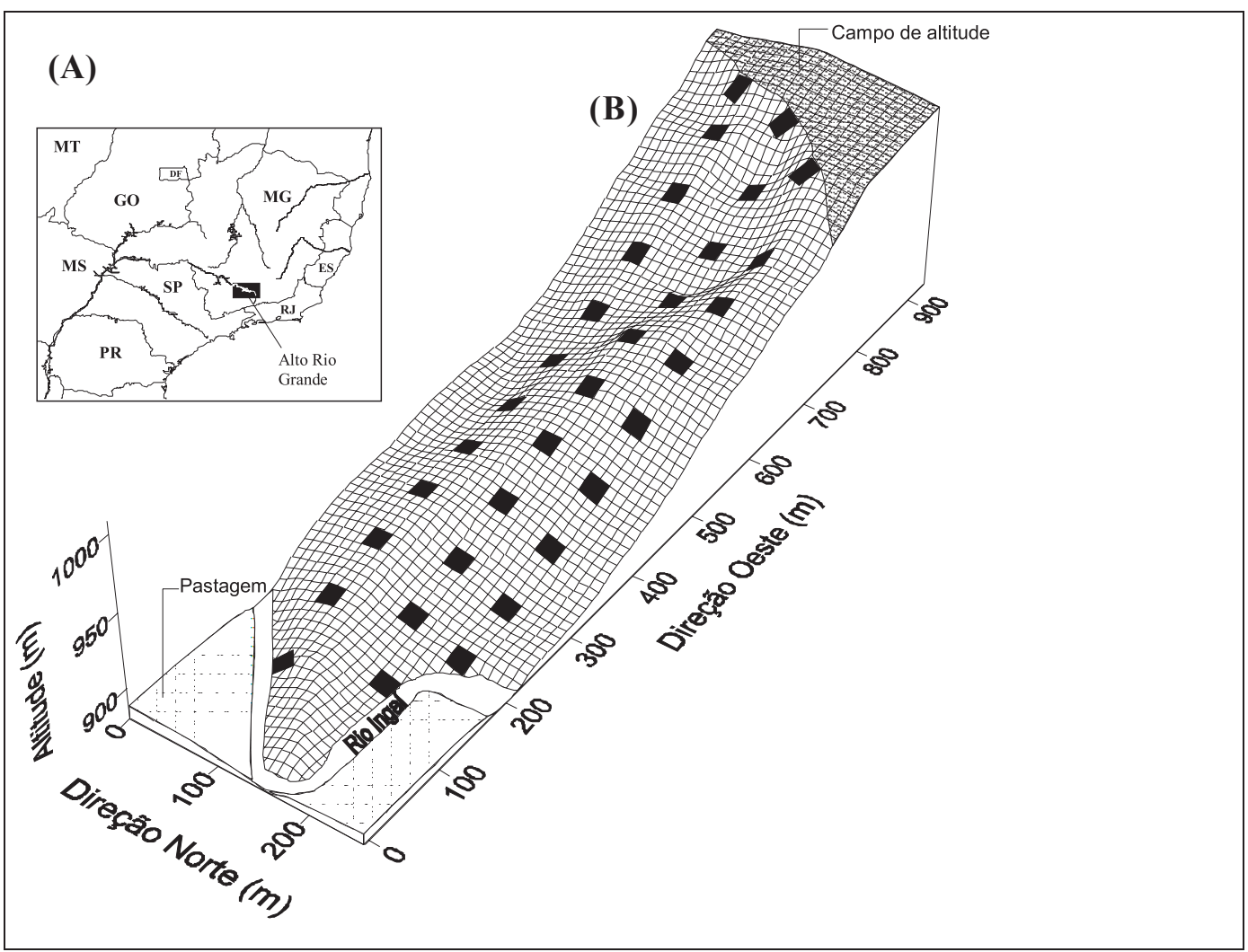

Figura 1. Situação geográfica da Região do Alto Rio Grande (A) Mapa do Galego (Luminárias, MG) e mapa topográfico mostrando a disposição das 32 parcelas de $20 \times 20$ m (B). 
Tabela 1. Análises químicas e granulométricas dos solos da Mata do Galego (Luminárias, MG). Os números são médias \pm o desvio padrão de amostras superficiais ( 0 a $20 \mathrm{~cm}$ de profundidade) de 32 parcelas de $20 \times 20 \mathrm{~m}$.

\begin{tabular}{|c|c|c|c|}
\hline & \multicolumn{3}{|c|}{ Grupos de Solos } \\
\hline & $\begin{array}{c}\text { Argissolo } \\
\text { Vermelho fase } \\
\text { média fertilidade }\end{array}$ & $\begin{array}{c}\text { Argissolo } \\
\text { Vermelho fase } \\
\text { baixa fertilidade }\end{array}$ & $\begin{array}{l}\text { Cambissolo } \\
\text { Háplico }\end{array}$ \\
\hline Altitude (m) & $915,82 \pm 17,26$ & $919,97 \pm 24,91$ & $980,13 \pm 13,39$ \\
\hline Desnível (m) & $6,67 \pm 2,26$ & $5,47 \pm 2,08$ & $11,03 \pm 3,21$ \\
\hline $\mathrm{pH}$ em $\mathrm{H}_{2} \mathrm{O}$ & $6,07 \pm 0,48$ & $4,95 \pm 0,31$ & $4,30 \pm 0,22$ \\
\hline $\mathrm{P}\left(\mathrm{mg} / \mathrm{dm}^{3}\right)$ & $1 \pm 0$ & $1,25 \pm 0,44$ & $2,5 \pm 0,84$ \\
\hline $\mathrm{K}\left(\mathrm{mg} / \mathrm{dm}^{3}\right)$ & $187,30 \pm 55,80$ & $57 \pm 24,63$ & $49,17 \pm 9,41$ \\
\hline $\mathrm{Ca}\left(\mathrm{cmolc} / \mathrm{dm}^{3}\right)$ & $3,367 \pm 0,87$ & $1,06 \pm 0,57$ & $0,5 \pm 0,14$ \\
\hline $\mathrm{Mg}\left(\mathrm{cmolc} / \mathrm{dm}^{3}\right)$ & $1,5 \pm 0,5$ & $0,635 \pm 0,49$ & $0,183 \pm 0,04$ \\
\hline $\mathrm{Ca}+\mathrm{Mg}\left(\mathrm{cmolc} / \mathrm{dm}^{3}\right)$ & $4,87 \pm 1,03$ & $1,70 \pm 1,03$ & $0,68 \pm 0,17$ \\
\hline $\mathrm{Al}\left(\mathrm{cmolc} / \mathrm{dm}^{3}\right)$ & $0,08 \pm 0,04$ & $0,86 \pm 0,39$ & $2,28 \pm 0,81$ \\
\hline $\mathrm{Ca}+\mathrm{Mg} / \mathrm{Al}\left(\mathrm{cmolc} / \mathrm{dm}^{3}\right)$ & $41,83 \pm 22,62$ & $3,36 \pm 3,94$ & $0,33 \pm 0,14$ \\
\hline Soma de bases $\left(\mathrm{cmolc} / \mathrm{dm}^{3}\right)$ & $5,33 \pm 0,97$ & $1,84 \pm 1,06$ & $0,8 \pm 0,18$ \\
\hline Saturação por bases (\%) & $48,05 \pm 7,10$ & $17,04 \pm 9,11$ & $5,72 \pm 1,33$ \\
\hline Saturação por alumínio (\%) & $1,55 \pm 0,82$ & $35,94 \pm 20,42$ & $72,77 \pm 7,76$ \\
\hline Matéria orgânica (dag/kg) & $3,48 \pm 0,93$ & $3,13 \pm 0,63$ & $4,10 \pm 2,00$ \\
\hline Areia $(\%)$ & $22,17 \pm 7,19$ & $32,20 \pm 10,00$ & $49,67 \pm 6,19$ \\
\hline Argila (\%) & $31,1 \pm 9,55$ & $32,8 \pm 6,26$ & $18,5 \pm 3,7$ \\
\hline Silte (\%) & $39,4 \pm 7,94$ & $35,1 \pm 6,88$ & $32,8 \pm 5,5$ \\
\hline
\end{tabular}

ser considerado alto se comparado com outros levantamentos realizados na Bacia do Rio Grande, como o de Madre de Deus de Minas, em fragmento de 20 ha, e o da Reserva Poço Bonito, em área de 70 ha, com 192 e 219 espécies, respectivamente (Oliveira Filho et al. 1994e). Outros levantamentos florísticos na mesma região tiveram riqueza superior ao da Mata do Galego, como, por exemplo, o da mata da Fazenda Botelho (84 ha), em Bom Sucesso (MG), com 245 espécies (Carvalho et al. 1995a), e o da mata de Itutinga (3,5 ha) com 253 espécies (Vilela et al. 1995).

Os gêneros com maior número de espécies foram: Ocotea (seis), Machaerium (cinco), Myrcia (cinco), Cordia (quatro) Nectandra (quatro) e Miconia (quatro) que, juntos, contribuíram com $14,5 \%$ das espécies. Esses gêneros também foram bem representados em outros levantamentos realizados em Lavras (Oliveira Filho et al. 1994b), Bom Sucesso (Carvalho et al. 1995a) e Itutinga (Vilela et al. 1995).
Entre as 57 famílias encontradas, 22 foram representadas por apenas uma espécie. As famílias com maior riqueza foram: Myrtaceae (20), Lauraceae (14), Fabaceae Faboideae (11), Rubiaceae (11), Euphorbiaceae (10), Fabaceae Mimosoideae (10), Malvaceae (sete), Melastomataceae (sete), Annonaceae (seis), Rutaceae (seis) e Vochysiaceae (cinco). Essas 13 famílias possuem, juntas, $53,5 \%$ das espécies. Em estudos de florestas mesófilas semidecíduas dos Estados de São Paulo (Gandolfi et al. 1995) e Minas Gerais (Carvalho et al. 1996; Carvalho et al. 2000), também foi observado que um número pequeno de famílias apresenta a maior parte das espécies.

Entre as famílias com maior riqueza florística na Mata do Galego, apenas Vochysiaceae e Malvaceae não estão entre as famílias com maior número de espécies em outros trabalhos da região (Oliveira Filho et al. 1994b; Oliveira Filho et al. 1994e; Carvalho et al. 1995a). No caso da Malvaceae, esse fato 
Tabela 2. Famílias e espécies da vegetação arbórea amostradas na Mata do Galego, Luminárias, MG e respectivos registros no Herbário da ESAL.

\begin{tabular}{lc}
\hline Família/Espécie & Registro \\
& ESAL \\
\hline
\end{tabular}

\begin{tabular}{ll}
\hline ANACARDIACEAE & \\
Lithraea molleoides (Vell.) Engler & 16364 \\
Tapirira guianensis Aubl. & 16365 \\
T. obtusa (Benth.) Mitchell & 16366 \\
ANNONACEAE &
\end{tabular}

ANNONACEAE

Annona cacans Warm.

16367

Guatteria nigrescens Mart.

16370

Rollinia laurifolia Schltdl.

16371

R. sericea (R. E. Fries) R. E. Fries

16372

R. sylvatica (A. St.-Hil.) Mart.

16373

Xylopia brasiliensis Sprengel

16374

APOCYNACEAE

Aspidosperma parvifolium A. DC.

16376

A. polyneuron Müll.Arg.

A. spruceanum Benth.

16377

16635

AQUIFOLIACEAE

Ilex brevicuspis Reissek

I. cerasifolia Reissek

I. conocarpa Reissek

16379

16380

16381

ARALIACEAE

Dendropanax affinis (E. Marchal)

16382

Gamerro \& Zuloaga

D. cuneatus (DC.) Decne \& Planchon

Schefflera acuminata (E. Marchal) D. Frodin

ARECACEAE

Geonoma schottiana Mart.

16385

ASTERACEAE

Eremanthus erythropappus (DC.) MacLeish

Piptocarpha macropoda Baker

16417

Vernonanthura diffusa (Less.) H.Robinson

16423

16424

BIGNONIACEAE

Jacaranda macrantha Cham.

Tabebuia ochracea (Cham.) Rizz.

T. serratifolia (Vahl) Nichols

16390

16391

16392

BORAGINACEAE

Cordia ecalyculata Vell.

16395

C. sellowiana Cham.

16396

C. superba Cham.

C. trichotoma (Vell.) Arrab.

14618

16397

BURSERACEAE

Protium heptaphyllum (Aublet) Marchand

P. spruceanum (Benth.) Engler

16398

16399

P. widgrenii Engler

16400

CECROPIACEAE

Cecropia glaziovii Snethl.
Tabela 2 (continuação)

Família/Espécie

Registro

ESAL

CECROPIACEAE

Cecropia pachystachya Trécul

16404

CELASTRACEAE

Maytenus ilicifolia Mart.

16405

M. glazioviana Loes.

M. salicifolia Reissek

16406

16407

CELTIDACEAE

Celtis iguanaea (Jacquin) Sargent

16618

CHRYSOBALANACEAE

Hirtella hebeclada Moric.

16408

CLETHRACEAE

Clethra scabra Pers.

CLUSIACEAE

Calophyllum brasiliense Cambess.

Garcinia gardneriana (Planchon \&

Triana) Zappi

Kielmeyera lathrophyton Saddi

Vismia brasiliensis Choisy

16409

16453

16454

16455

16453

COMBRETACEAE

Terminalia glabrescens Mart.

16410

CONNARACEAE

Connarus regnellii $\mathrm{G}$. Schelenb.

16427

CUNONIACEAE

Lamanonia ternata Vell.

16428

EBENACEAE

Diospyros inconstans Jacquin

16431

ELAEOCARPACEAE

Sloanea monosperma Vell.

16432

EUPHORBIACEAE

Actinostemon concolor (Spreng.) Müll. Arg. 16434

A. klotzschii (Didrichs) Pax 16435

Alchornea triplinervea (Spreng.) Müll. Arg. 16437

Croton floribundus Sprengel 16439

C. urucurana Baillon

16440

Hyeronima ferruginea Müll. Arg. $\quad 16441$

Pera glabrata (Schott) Poepp. $\quad 16442$

Sapium glandulosum (L.) Morong 16443

Sebastiania commersoniana (Bail) $\quad 16444$

Sm. \& Downs

S. schottiana (Müll. Arg.) Müll. Arg.

16445

FABACEAE CAESALPINIOIDEAE

Bauhinia longifolia (Bongard) Steudel $\quad 16489$

Copaifera langsdorffii Desf. $\quad 16491$

Sclerolobium rugosum Mart. 16494

Senna macranthera (Vell.) Irwin \& Barneby 16496

S. multijuga (L. C. Rich.) Irwin \& Barneby 16497 
Tabela 2 (continuação)

Família/Espécie

FABACEAE FABOIDEAE

Dalbergia miscolobium Benth.

D. villosa (Benth.) Benth.

Deguelia hatschbachii Az. Tozzi

Lonchocarpus cultratus (Vell.) Az.

Tozzi \& H. C. Lima

Machaerium brasiliense Vogel

M. hirtum (Vell.) Stellfeld

$M$. nictitans (Vell.) Benth.

M. stipitatum Vogel

M. villosum Vogel

Platycyamus regnellii Benth.

Platypodium elegans Vogel

FABACEAE MIMOSOIDEAE

Acacia glomerosa Benth.

A. recurva Benth.

Albizia polycephala (Benth.) Killip

Inga ingoides (Rich.) Willd.

I. striata Benth.

I. vera Willd.

Leucochloron incuriale (Vell.) Barneby \&

Grimes

Mimosa scabrela Benth.

Piptadenia gonoacantha (Mart.) Macbr.

Stryphnodendron adstringens (Mart.) Cov.

FLACOURTIACEAE

Casearia decandra Jacquin

C. lasiophylla Eichler

C. sylvestris Swartz

Xylosma ciliatifolium (Clos) Eichler

ICACINACEAE

Citronella paniculata (Mart.) Howard

LACISTEMATACEAE

Lacistema hasslerianum Chodat

LAURACEAE

Cryptocarya aschersoniana $\mathrm{Mez}$

Endlicheria paniculata (Sprengel) Macbr.

Nectandra grandiflora Nees

N. megapotamica (Sprengel) Mez

$N$. nitidula Nees

N. oppositifolia Nees

Ocotea corymbosa (Meisner) Mez

O. diospyrifolia (Meisner) Mez

O. elegans $\mathrm{Mez}$

O. indecora (Schott) $\mathrm{Mez}$

O. odorifera (Vell.) Rohwer

O. pulchella Mart.

O. velutina (Nees) Rohwer

Persea pyrifolia Nees \& Mart.
Registro

ESAL

16511

16512

16513

16515

16516

16517

16518

16519

16520

16523

16524

16498

16499

16501

16502

16503

16504

16505

16506

16507

16508

16446

16447

16448

16449

16457

16460

16526

16527

16528

16529

16530

16531

16532

16533

16534

16525

16535

16536

16537

16538
Tabela 2 (continuação)

Família/Espécie

Registro

ESAL

\section{LECYTHIDACEAE}

Cariniana estrellensis (Raddi) Kuntze

16461

LOGANIACEAE

Strychnos brasiliensis (Sprengel) Mart.

16462

LYTHRACEAE

Lafoensia pacari A. St.-Hil.

16464

MALPIGHIACEAE

Byrsonima laxiflora Griseb.

16541

MALVACEAE

Ceiba speciosa (A. St.-Hil.) Gibbs \& Semir 16393

Eriotheca candolleana (K. Schum.) A. Robyns 16394

Guazuma ulmifolia Lam.

16609

Helicteres ovata Lam.

16610

Luehea candicans Mart.

16615

L. divaricata Mart. \& Zucc.

16616

L. grandiflora Mart. \& Zucc.

16617

MELASTOMATACEAE

Leandra scabra DC.

16544

Miconia cinnamomifolia (DC.) Naudin

16546

M. ligustroides (DC.) Naudin

16547

M. pepericarpa $\mathrm{DC}$.

16548

M. trianae Cogn.

16549

Tibouchina stenocarpa (DC.) Cogn.

16550

Trembleya parviflora (D. Don) Cogn.

16551

MELIACEAE

Cabralea canjerana (Vell) Mart.

16552

Cedrela fissilis Vell.

16553

Guarea kunthiana A. Juss.

16554

Trichilia emarginata (Turcz.) C. DC.

16556

T. pallida Swartz

16557

MONIMIACEAE

Mollinedia argyrogyna Perkins

16558

M. widgrenii A. DC.

16559

MORACEAE

Maclura tinctoria (L.) D. Don.

16562

MYRSINACEAE

Myrsine coriacea (Sw.) R. Br.

16563

M. guianensis (Aublet) Kuntze

16564

M. umbellata Mart.

16565

MYRTACEAE

Calycorectes acutatus (Miq.) Toledo 16465

Calyptranthes brasiliensis Sprengel 16466

C. clusiifolia (Miq.) O. Berg 16467

Campomanesia guazumifolia (Cambess.) 16469

O. Berg

C. velutina $\mathrm{O}$. Berg

C. xanthocarpa O. Berg 
Tabela 2 (continuação)

\begin{tabular}{lc}
\hline Família/Espécie & $\begin{array}{c}\text { Registro } \\
\text { ESAL }\end{array}$ \\
\hline
\end{tabular}

\section{MYRTACEAE}

Eugenia florida DC.

16473

E. hiemalis Cambess.

Gomidesia affinis (Cambess.) Legrand

Marlierea racemosa (Vell.) Kiaersk.

Myrcia breviramis (O. Berg) Legrand

M. fallax (Rich.) DC.

M. multiflora (Lam.) DC.

$M$. rostrata $\mathrm{DC}$.

M. tomentosa (Aubl.) DC.

$M$. velutina $\mathrm{O}$. Berg

Myrciaria floribunda (West) O. Berg

Psidium cattleyanum Sab.

P. rufum Mart.

Siphoneugena densiflora $\mathrm{O}$. Berg

NYCTAGINACEAE

Guapira opposita (Vell.) Reitz

Pisonia zapallo Griseb.

16474

16476

16468

16477

16633

16478

16479

16480

16481

16482

16483

16484

16485

16486

16487

PIPERACEAE

Piper arboreum Aublet

P. gaudichaudianum Kunth

16566

16567

PROTEACEAE

Euplassa incana (Klotzsch) Johnston

16570

Roupala montana Aublet

16571

RHAMNACEAE

Rhamnus sphaerosperma Swartz

16572

ROSACEAE

Prunus brasiliensis (Cham. \& Schl.) D. Dietr. 16573

P. myrtifolia (L.) Urban

16574

P. sellowii Koehne

16575

\section{RUBIACEAE}

Alibertia macrophylla K. Schum.

16577

Amaioua guianensis Aublet

16578

Chomelia sericea Müll. Arg.

16581

Coutarea hexandra (Jacquin) K. Schum.

Faramea cyanea Müll. Arg.

16579

16580

Guettarda uruguensis Cham. \& Schltdl. $\quad 16582$

Ixora warmingii Müll. Arg.

Psychotria carthagenensis Jacquin

P. hastisepala Müll. Arg.

P. sessilis (Vell.) Müll. Arg.

16583

16585

16587

16588

RUBIACEAE

Randia nitida (Kunth) DC.

16589

RUTACEAE

Esenbeckia febrifuga (A. St.-Hil.) A. Juss. Galipea jasminiflora (A. St.-Hil.) Engler Metrodorea stipularis Mart.
Tabela 2 (continuação)

$\begin{aligned} & \text { Família/Espécie } \text { Registro } \\ & \text { ESAL }\end{aligned}$

\section{RUTACEAE}

Zanthoxylum caribaeum Lam.

16595

Z. fagara (L.) Sargent

16596

Z. rhoifolium Lam.

16598

\section{SAPINDACEAE}

Cupania vernalis Cambess. $\quad 16599$

Matayba elaeagnoides Radlk. $\quad 16600$

M. guianensis Aublet $\quad 16601$

M. juglandifolia (Cambess.) Radlk. $\quad 16602$

SAPOTACEAE

Chrysophyllum marginatum (Hooker \&

16603

Arnot) Radlk.

SIPARUNACEAE

Siparuna guianensis Aublet

16560

SOLANACEAE

Cestrum laevigatum Schltdl.

16604

STYRACACEAE

Styrax latifolius Pohl

16611

THEACEAE

Ternstroemia brasiliensis Cambess.

16612

THYMELAEACEAE

Daphnopsis brasiliensis Mart. \& Zucc. 16613

D. fasciculata (Meisner) Nevling 16614

ULMACEAE

Trema micrantha (L.) Blume

16619

VERBENACEAE

Aegiphila sellowiana Cham. 16620

Vitex cymosa Bert. $\quad 16623$

V. polygama Cham. 16624

VOCHYSIACEAE

Callisthene major Mart. 16625

Qualea dichotoma (Mart.) Warm. 16626

Q. multiflora Mart. 16627

Vochysia thyrsoidea Pohl 16629

V. tucanorum Mart. $\quad 16630$

se deve ao sistema de classificação de espécies adotado no presente trabalho, que inclui nessa família, espécies pertencentes a outras famílias (Sterculiaceae, Bombacaceae e Tiliaceae) no sistema de classificação de Cronquist (1981).

Já a riqueza apresentada por Vochysiaceae pode ser devida à influência de formações vegetais próximas ao fragmento, como cerrado e campos rupestres. Isso se evidencia pela 
presença de espécies como Eremanthus erythropappus, típica de campos rupestres (Oliveira Filho et al. 1994a), e Vochysia tucanorum, Qualea multiflora e Vochysia thyrsoidea, que ocorrem em áreas de cerrado (Lorenzi 1992; Rossi et al. 1998). Esta última, em particular, ocorre em cerrados de maior altitude, marcando transição para campos rupestres em várias regiões serranas (Oliveira Filho \& Fluminhan Filho 1999). A influência da vegetação adjacente sobre a composição florística de florestas já foi observada em outros estudos, como o de Oliveira Filho et al. (1994a), na Reserva Biológica do Poço Bonito (Lavras, MG), e no de Cesar \& Leitão Filho (1990) na mata da Fazenda Barreiro Rico (Anhembi, SP).

Além da influência das formações vegetais adjacentes, a composição florística, de forma geral, pode ser influenciada por vários fatores em diferentes escalas. O clima, por exemplo, é considerado um dos principais fatores, atuando na composição florística em níveis regionais (Ledru 1993). Em escalas locais, a altitude, profundidade e composição química do solo, topografia, microambientes, entre outros, têm sido apontados como importantes na seleção e no estabelecimento das espécies (Pagano \& Leitão Filho 1987; Rodrigues et al. 1989).

Algumas espécies amostradas na Mata do Galego são consideradas como de tolerância ampla e ocorrem em diferentes formações vegetais. Algumas, como Coutarea hexandra e Cordia trichotoma, ocorrem tanto em habitats mais úmidos (como em florestas ao longo do Rio Amazonas) quanto às margens de cursos d'água efêmeros na Caatinga. Outras espécies encontradas em áreas de Caatinga são Aspidosperma polyneuron, que ocorre também em florestas mesófilas das regiões Sul e Sudeste, e Platypodium elegans, que é encontrada também em florestas sazonais no Panamá e em cerrados do Brasil Central (Prado \& Gibbs 1993). Outras espécies com ampla distribuição no Brasil são: Casearia sylvestris, Copaifera langsdorffii, Guazuma ulmifolia, Machaerium stipitatum, Maclura tinctoria, Trema micrantha e Zanthoxylum rhoifolium (Corrêa 1975; Lorenzi 1992).

A ocorrência de espécies em habitats com condições ambientais variadas pode ser não somente devida a sua ampla tolerância, mas também à presença de microambientes, como, por exemplo, clareiras ou sítios mais ou menos úmidos, que permitem o estabelecimento dessas espécies (Rodrigues \& Araújo 1997). O que confirma essas premissas é o fato de que algumas espécies, apesar de terem ampla distribuição, exigem condições de habitat restritas, como, por exemplo, Protium spruceanum, que ocorre nas florestas úmidas Atlânticas e Amazônicas, e que, na região do Cerrado, é encontrada exclusivamente em matas ciliares; e a palmeira Geonoma schottiana, que ocorre em locais de solos úmidos, mas não saturados (Oliveira Filho \& Ratter 2000).

Essa complexa distribuição das espécies tem despertado grande interesse de pesquisadores, que buscam respostas para a distribuição atual das formações vegetais por meio de ligações florísticas entre elas, indicadas pelas espécies de ampla distribuição, e por mudanças climáticas ocorridas no passado. Em estudo sobre a distribuição de mais de oitenta táxons na América do Sul, Prado \& Gibbs (1993) mostraram existir estreita ligação entre a vegetação da Caatinga e do Chaco argentino por meio de espécies que atravessam o Brasil, ocorrendo em áreas de matas sazonais na região do Cerrado, indicando a existência de formação vegetal decídua contínua no passado. Estudos palinológicos, realizados por Ledru (1993), reforçam essa ligação e indicam que talvez essa formação vegetal contínua tenha alcançado sua extensão máxima durante um período de clima seco e frio do Pleistoceno.

Em estudo que investigou ligações florísticas das florestas ciliares do Brasil Central com outras formações florestais da América do Sul, Oliveira Filho \& Ratter (2000) observaram que grande parte das espécies de matas ciliares 
(77\%) é compartilhada com florestas ombrófilas Amazônicas e florestas Atlânticas, e parte menor é comum com cerradões e florestas decíduas.

Levantamento estrutural - A fisionomia da Mata do Galego é caracterizada por espécies emergentes com 15 a $18 \mathrm{~m}$ de altura, como Copaifera langsdorffii, Diospyros inconstans, Lithraea molleoides, Machaerium stipitatum, M. villosum e Sclerolobium rugosum; e por grande número de espécies com 10 a 14m, como Casearia sylvestris, Cupania vernalis, Faramea cyanea, Machaerium hirtum, M. stipitatum, Roupala montana, Tapirira guianensis e T. obtusa. Com alturas de 6 a 9m, citam-se Galipea jasminiflora e Nectandra nitidula.

No levantamento estrutural, foram amostrados 2.343 indivíduos de 159 espécies, pertencentes a 50 famílias e 104 gêneros (Tab. 3). As espécies mais abundantes foram Lithraea molleoides, Casearia sylvestris, Machaerium stipitatum, Faramea cyanea, Diospyros inconstans e Copaifera langsdorffii. Em conjunto, elas representam $30,76 \%$ dos indivíduos amostrados. Entre essas espécies, apenas Faramea cyanea apresentou baixa freqüência, indicando distribuição agrupada dos indivíduos. Ela ocorreu somente em 10 parcelas, localizadas em áreas de declive mais acentuado, sobre Cambissolo Háplico, o que sugere adaptação dessa espécie a esse tipo de ambiente.

Os maiores valores de VI variaram entre 16,57 e 11,53 , e pertencem a apenas quatro espécies. A espécie com maior valor de importância foi Lithraea molleoides, que apresentou alta densidade e dominância. Já as espécies Casearia sylvestris e Machaerium stipitatum apresentaram baixa dominância, mas alta densidade. A espécie Copaifera langsdorffii apresentou o segundo maior valor de dominância relativa, o que contribuiu para que ela apresentasse o quarto maior valor de VI.
As espécies mais abundantes e de maior VI da Mata do Galego, em geral, têm sido bem representadas em florestas da região, exceto Diospyros inconstans e Lithraea molleoides. Em uma comparação florística entre quarenta e três levantamentos florísticos e estruturais de florestas ciliares do Brasil extra amazônico, D. inconstans foi amostrada em apenas um deles (Rodrigues \& Nave 2000), que foi o estudo realizado na mata de Bom Sucesso, região do Alto Rio Grande (Carvalho et al. 1995a).

A espécie L. molleoides tem sido amostrada em outros levantamentos da região, porém em baixa densidade (Vilela et al. 1994; Carvalho et al. 1995b; Oliveira Filho et al. 1994a; Oliveira Filho et al. 1994b). Essa espécie é considerada como indicadora de solos férteis (Ratter et al. 1978) e, embora no presente estudo ela tenha ocorrido em 21 parcelas, o número de indivíduos variou muito entre parcelas e a parcela em que ocorreu o maior número de indivíduos dessa espécie (34) apresentou alta fertilidade. A alta densidade de L. molleoides na Mata do Galego pode estar relacionada ao histórico de perturbação da área, pois essa espécie ocorre principalmente em formações florestais secundárias (Lorenzi 1992).

As espécies Casearia sylvestris e Machaerium stipitatum são consideradas como espécies de alta densidade e ampla distribuição, apresentando, geralmente, populações numerosas nas formações ciliares (Durigan et al. 2000).

A espécie Copaifera langsdorffii é considerada como generalista por habitat (Oliveira Filho \& Ratter 2000) e, em geral, é dominante na fisionomia da maioria dos remanescentes florestais do Centro-Sul de Minas Gerais (Oliveira Filho et al. 1994b). Em matas de galeria do Distrito Federal, C. langsdorffii tem distribuição ampla, mas com maior densidade em áreas mais secas (Sampaio et al. 1997; Felfili 1998). Essa espécie foi considerada por Durigan et al. (2000) como pertencente a um grupo de espécies com densidade variável e distribuição ampla, podendo ser mais abundante 
Tabela 3. Espécies arbóreas com CAP $\geq 15,5 \mathrm{~cm}$, amostradas em 32 parcelas de 20 x $20 \mathrm{~m}$ (1,28 ha), na Mata do Galego (Luminárias, $\mathrm{MG}$ ), com seus respectivos parâmetros fitossociológicos. $\mathrm{N}=$ número de indivíduos; $\mathrm{P}=$ número de parcelas onde a espécie ocorre; $\mathrm{AB}=$ área basal; $\mathrm{D}=$ diâmetro máximo; $\mathrm{H}=$ altura máxima; $\mathrm{DA}=$ densidade absoluta (indivíduos/ha); FA = freqüência absoluta; DoA = dominância absoluta; VI = valor de importância. As espécies estão ordenadas pelos valores decrescentes de VI.

\begin{tabular}{|c|c|c|c|c|c|c|c|c|c|}
\hline Espécies & $\mathrm{N}$ & $\mathrm{P}$ & $\begin{array}{l}\mathrm{AB} \\
\left(\mathrm{m}^{2}\right)\end{array}$ & $\begin{array}{c}\mathrm{D} \\
(\mathrm{cm})\end{array}$ & $\begin{array}{c}\mathrm{H} \\
(\mathrm{m})\end{array}$ & $\begin{array}{c}\text { DA } \\
\text { (I/ha) }\end{array}$ & $\begin{array}{l}\text { FA } \\
(\%)\end{array}$ & $\begin{array}{c}\text { DoA } \\
\left(\mathrm{m}^{2} / \mathrm{ha}\right)\end{array}$ & VI \\
\hline Lithraea molleoides & 147 & 21 & 2,895 & 37,5 & 15,0 & 114,8 & 65,63 & 2,262 & 16,57 \\
\hline Casearia sylvestris & 176 & 29 & 1,044 & 24,7 & 14,0 & 137,5 & 90,63 & 0,815 & 13,58 \\
\hline Machaerium stipitatum & 124 & 26 & 1,282 & 28,5 & 15,0 & 96,9 & 81,25 & 1,002 & 11,69 \\
\hline Copaifera langsdorffii & 79 & 22 & 2,078 & 66,8 & 18,0 & 61,7 & 68,75 & 1,623 & 11,53 \\
\hline Faramea cyanea & 104 & 10 & 1,212 & 27,2 & 12,0 & 81,3 & 31,25 & 0,947 & 8,88 \\
\hline Diospyros inconstans & 91 & 24 & 0,728 & 28,6 & 15,0 & 71,1 & 75,00 & 0,569 & 8,54 \\
\hline Ocotea velutina & 42 & 17 & 1,629 & 62,6 & 15,0 & 32,8 & 53,13 & 1,272 & 8,16 \\
\hline Guazuma ulmifolia & 48 & 20 & 0,979 & 31,3 & 14,5 & 37,5 & 62,50 & 0,765 & 6,95 \\
\hline Machaerium villosum & 40 & 15 & 1,302 & 65,3 & 18,0 & 31,3 & 46,88 & 1,017 & 6,95 \\
\hline Cupania vernalis & 70 & 25 & 0,325 & 14,0 & 12,0 & 54,7 & 78,13 & 0,254 & 6,64 \\
\hline Machaerium nictitans & 28 & 12 & 1,305 & 48,4 & 18,0 & 21,9 & 37,50 & 1,019 & 6,12 \\
\hline Tapirira obtusa & 42 & 11 & 1,064 & 33,7 & 16,0 & 32,8 & 34,38 & 0,831 & 5,94 \\
\hline Machaerium hirtum & 59 & 10 & 0,823 & 30,7 & 14,0 & 46,1 & 31,25 & 0,643 & 5,89 \\
\hline Tapirira guianensis & 47 & 15 & 0,687 & 38,4 & 16,0 & 36,7 & 46,88 & 0,537 & 5,55 \\
\hline Roupala montana & 44 & 16 & 0,670 & 31,8 & 12,0 & 34,4 & 50,00 & 0,523 & 5,49 \\
\hline Albizia polycephala & 38 & 16 & 0,677 & 24,6 & 15,0 & 29,7 & 50,00 & 0,529 & 5,25 \\
\hline Myrsine umbellata & 51 & 18 & 0,323 & 15,9 & 14,5 & 39,8 & 56,25 & 0,253 & 5,05 \\
\hline Sclerolobium rugosum & 19 & 4 & 1,153 & 62,1 & 18,0 & 14,8 & 12,50 & 0,901 & 4,43 \\
\hline Actinostemon concolor & 45 & 13 & 0,309 & 19,2 & 15,0 & 35,2 & 40,63 & 0,241 & 4,20 \\
\hline Vismia brasiliensis & 28 & 14 & 0,496 & 25,2 & 17,0 & 21,9 & 43,75 & 0,388 & 4,11 \\
\hline Chrysophyllum marginatum & 34 & 16 & 0,261 & 19,2 & 12,0 & 26,6 & 50,00 & 0,204 & 3,93 \\
\hline Cryptocarya aschersoniana & 19 & 7 & 0,735 & 48,9 & 13,0 & 14,8 & 21,88 & 0,574 & 3,61 \\
\hline Pera glabrata & 25 & 13 & 0,384 & 31,0 & 17,0 & 19,5 & 40,63 & 0,300 & 3,56 \\
\hline Bauhinia longifolia & 35 & 14 & 0,186 & 15,9 & 13,0 & 27,3 & 43,75 & 0,146 & 3,55 \\
\hline Myrcia rostrata & 27 & 16 & 0,186 & 20,7 & 10,5 & 21,1 & 50,00 & 0,146 & 3,43 \\
\hline Rollinia sericea & 30 & 11 & 0,323 & 34,6 & 14,0 & 23,4 & 34,38 & 0,253 & 3,38 \\
\hline Nectandra megapotamica & 20 & 6 & 0,672 & 38,5 & 15,0 & 15,6 & 18,75 & 0,525 & 3,37 \\
\hline Croton floribundus & 25 & 10 & 0,406 & 25,8 & 16,0 & 19,5 & 31,25 & 0,317 & 3,29 \\
\hline Aspidosperma parvifolium & 10 & 7 & 0,688 & 58,4 & 16,5 & 7,8 & 21,88 & 0,538 & 3,10 \\
\hline Ocotea corymbosa & 17 & 12 & 0,381 & 40,3 & 15,0 & 13,3 & 37,50 & 0,297 & 3,10 \\
\hline Miconia cinnamomifolia & 24 & 11 & 0,310 & 42,6 & 15,0 & 18,8 & 34,38 & 0,242 & 3,09 \\
\hline Eugenia florida & 27 & 9 & 0,326 & 20,0 & 14,0 & 21,1 & 28,13 & 0,255 & 3,04 \\
\hline Cedrela fissilis & 14 & 9 & 0,489 & 42,3 & 18,0 & 10,9 & 28,13 & 0,382 & 2,94 \\
\hline Luehea grandiflora & 16 & 13 & 0,299 & 36,6 & 15,0 & 12,5 & 40,63 & 0,234 & 2,94 \\
\hline Casearia lasiophylla & 26 & 11 & 0,141 & 14,0 & 12,0 & 20,3 & 34,38 & 0,110 & 2,71 \\
\hline Lonchocarpus cultratus & 8 & 7 & 0,537 & 38,5 & 17,0 & 6,3 & 21,88 & 0,420 & 2,59 \\
\hline Tabebuia serratifolia & 15 & 11 & 0,269 & 26,7 & 15,0 & 11,7 & 34,38 & 0,210 & 2,59 \\
\hline Persea pyrifolia & 9 & 7 & 0,463 & 40,6 & 15,0 & 7,0 & 21,88 & 0,362 & 2,43 \\
\hline Ceiba speciosa & 6 & 6 & 0,546 & 81,2 & 12,0 & 4,7 & 18,75 & 0,427 & 2,42 \\
\hline Rollinia laurifolia & 15 & 10 & 0,218 & 29,0 & 14,0 & 11,7 & 31,25 & 0,170 & 2,34 \\
\hline Dalbergia villosa & 12 & 7 & 0,366 & 45,0 & 14,5 & 9,4 & 21,88 & 0,286 & 2,29 \\
\hline Coutarea hexandra & 20 & 10 & 0,094 & 13,7 & 14,0 & 15,6 & 31,25 & 0,074 & 2,22 \\
\hline Maclura tinctoria & 14 & 9 & 0,216 & 25,5 & 13,0 & 10,9 & 28,13 & 0,168 & 2,18 \\
\hline Casearia decandra & 15 & 10 & 0,150 & 26,8 & 13,0 & 11,7 & 31,25 & 0,117 & 2,15 \\
\hline Clethra scabra & 25 & 3 & 0,226 & 26,9 & 11,0 & 19,5 & 9,38 & 0,177 & 2,02 \\
\hline
\end{tabular}


Tabela 3. (continuação)

\begin{tabular}{|c|c|c|c|c|c|c|c|c|c|}
\hline Espécies & $\mathrm{N}$ & $\mathrm{P}$ & $\begin{array}{l}\mathrm{AB} \\
\left(\mathrm{m}^{2}\right)\end{array}$ & $\begin{array}{c}\mathrm{D} \\
(\mathrm{cm})\end{array}$ & $\begin{array}{c}\mathrm{H} \\
(\mathrm{m})\end{array}$ & $\begin{array}{c}\text { DA } \\
\text { (I/ha) }\end{array}$ & $\begin{array}{l}\text { FA } \\
(\%)\end{array}$ & $\begin{array}{c}\text { DoA } \\
\left(\mathrm{m}^{2} / \mathrm{ha}\right)\end{array}$ & VI \\
\hline Guatteria nigrescens & 16 & 9 & 0,114 & 16,9 & 12,0 & 12,5 & 28,13 & 0,089 & 1,99 \\
\hline Guettarda uruguensis & 12 & 7 & 0,240 & 33,8 & 10,0 & 9,4 & 21,88 & 0,187 & 1,94 \\
\hline Myrcia tomentosa & 15 & 8 & 0,154 & 22,9 & 14,0 & 11,7 & 25,00 & 0,120 & 1,94 \\
\hline Rollinia sylvatica & 24 & 4 & 0,145 & 13,9 & 12,5 & 18,8 & 12,50 & 0,114 & 1,87 \\
\hline Ixora warmingii & 15 & 9 & 0,066 & 12,1 & 9,0 & 11,7 & 28,13 & 0,052 & 1,81 \\
\hline Cariniana estrellensis & 6 & 4 & 0,395 & 47,1 & 17,0 & 4,7 & 12,50 & 0,309 & 1,79 \\
\hline Myrcia multiflora & 14 & 9 & 0,072 & 14,9 & 10,0 & 10,9 & 28,13 & 0,056 & 1,79 \\
\hline Dendropanax cuneatus & 16 & 8 & 0,050 & 9,6 & 14,0 & 12,5 & 25,00 & 0,039 & 1,70 \\
\hline Platycyamus regnellii & 8 & 8 & 0,167 & 26,6 & 16,0 & 6,3 & 25,00 & 0,131 & 1,68 \\
\hline Cordia ecalyculata & 12 & 8 & 0,078 & 14,3 & 14,0 & 9,4 & 25,00 & 0,061 & 1,61 \\
\hline Vochysia tucanorum & 11 & 5 & 0,205 & 28,9 & 13,0 & 8,6 & 15,63 & 0,160 & 1,59 \\
\hline Cordia sellowiana & 12 & 4 & 0,210 & 27,4 & 14,0 & 9,4 & 12,50 & 0,164 & 1,53 \\
\hline Cabralea canjerana & 7 & 6 & 0,193 & 32,3 & 14,0 & 5,5 & 18,75 & 0,151 & 1,49 \\
\hline Psychotria sessilis & 13 & 7 & 0,031 & 6,1 & 10,0 & 10,2 & 21,88 & 0,024 & 1,41 \\
\hline Amaioua guianensis & 11 & 6 & 0,096 & 20,4 & 14,0 & 8,6 & 18,75 & 0,075 & 1,40 \\
\hline Daphnopsis brasiliensis & 13 & 5 & 0,105 & 18,6 & 10,0 & 10,2 & 15,63 & 0,082 & 1,39 \\
\hline Maytenus ilicifolia & 13 & 6 & 0,061 & 11,6 & 10,0 & 10,2 & 18,75 & 0,047 & 1,38 \\
\hline Galipea jasminiflora & 14 & 5 & 0,062 & 9,8 & 8,5 & 10,9 & 15,63 & 0,048 & 1,32 \\
\hline Luehea divaricata & 6 & 5 & 0,182 & 37,6 & 13,0 & 4,7 & 15,63 & 0,142 & 1,31 \\
\hline Piptadenia gonoacantha & 11 & 3 & 0,183 & 28,7 & 12,0 & 8,6 & 9,38 & 0,143 & 1,30 \\
\hline Acacia glomerosa & 8 & 5 & 0,126 & 23,4 & 12,0 & 6,3 & 15,63 & 0,099 & 1,24 \\
\hline Chomelia sericea & 10 & 6 & 0,052 & 10,4 & 11,0 & 7,8 & 18,75 & 0,040 & 1,23 \\
\hline Siparuna guianensis & 8 & 7 & 0,021 & 6,8 & 9,0 & 6,3 & 21,88 & 0,016 & 1,17 \\
\hline Vitex polygama & 11 & 2 & 0,151 & 31,6 & 11,0 & 8,6 & 6,25 & 0,118 & 1,11 \\
\hline Alibertia macrophylla & 7 & 6 & 0,047 & 11,6 & 12,0 & 5,5 & 18,75 & 0,037 & 1,09 \\
\hline Eriotheca candolleana & 4 & 4 & 0,137 & 35,0 & 15,0 & 3,1 & 12,50 & 0,107 & 0,99 \\
\hline Nectandra nitidula & 7 & 5 & 0,046 & 16,3 & 8,0 & 5,5 & 15,63 & 0,036 & 0,98 \\
\hline Inga striata & 3 & 2 & 0,223 & 39,8 & 17,0 & 2,3 & 6,25 & 0,174 & 0,96 \\
\hline Matayba elaeagnoides & 7 & 5 & 0,041 & 12,7 & 11,0 & 5,5 & 15,63 & 0,032 & 0,96 \\
\hline Jacaranda macrantha & 6 & 2 & 0,167 & 33,7 & 15,0 & 4,7 & 6,25 & 0,130 & 0,94 \\
\hline Xylosma ciliatifolium & 6 & 4 & 0,087 & 17,7 & 11,0 & 4,7 & 12,50 & 0,068 & 0,94 \\
\hline Metrodorea stipularis & 7 & 2 & 0,136 & 33,0 & 14,0 & 5,5 & 6,25 & 0,107 & 0,90 \\
\hline Daphnopsis fasciculata & 6 & 4 & 0,057 & 17,8 & 11,0 & 4,7 & 12,50 & 0,045 & 0,85 \\
\hline Lamanonia ternata & 4 & 4 & 0,063 & 18,5 & 11,5 & 3,1 & 12,50 & 0,049 & 0,78 \\
\hline Marlierea racemosa & 5 & 4 & 0,044 & 19,1 & 11,0 & 3,9 & 12,50 & 0,034 & 0,77 \\
\hline Vitex cymosa & 3 & 2 & 0,148 & 25,5 & 15,0 & 2,3 & 6,25 & 0,116 & 0,76 \\
\hline Annona cacans & 3 & 3 & 0,103 & 25,9 & 16,0 & 2,3 & 9,38 & 0,081 & 0,74 \\
\hline Campomanesia guazumifolia & 4 & 3 & 0,079 & 22,0 & 10,0 & 3,1 & 9,38 & 0,062 & 0,72 \\
\hline Gomidesia affinis & 7 & 3 & 0,033 & 13,2 & 12,0 & 5,5 & 9,38 & 0,026 & 0,72 \\
\hline Citronella paniculata & 3 & 3 & 0,083 & 30,2 & 7,0 & 2,3 & 9,38 & 0,065 & 0,69 \\
\hline Mollinedia widgrenii & 5 & 4 & 0,014 & 7,2 & 8,0 & 3,9 & 12,50 & 0,011 & 0,69 \\
\hline Esenbeckia febrifuga & 4 & 4 & 0,018 & 9,0 & 9,0 & 3,1 & 12,50 & 0,014 & 0,66 \\
\hline Helicteres ovata & 3 & 2 & 0,111 & 36,9 & 6,0 & 2,3 & 6,25 & 0,087 & 0,66 \\
\hline Lacistema hasslerianum & 4 & 4 & 0,010 & 6,8 & 10,0 & 3,1 & 12,50 & 0,008 & 0,64 \\
\hline Platypodium elegans & 4 & 2 & 0,082 & 25,2 & 8,0 & 3,1 & 6,25 & 0,064 & 0,62 \\
\hline Calycorectes acutatus & 4 & 3 & 0,041 & 13,1 & 11,0 & 3,1 & 9,38 & 0,032 & 0,61 \\
\hline Ilex cerasifolia & 4 & 3 & 0,031 & 16,7 & 13,0 & 3,1 & 9,38 & 0,024 & 0,59 \\
\hline Leucochloron incuriale & 4 & 3 & 0,034 & 16,4 & 12,0 & 3,1 & 9,38 & 0,026 & 0,59 \\
\hline Campomanesia xanthocarpa & 3 & 3 & 0,042 & 15,9 & 12,0 & 2,3 & 9,38 & 0,033 & 0,57 \\
\hline Prunus brasiliensis & 4 & 3 & 0,024 & 12,3 & 10,0 & 3,1 & 9,38 & 0,019 & 0,57 \\
\hline
\end{tabular}


Tabela 3. (continuação)

\begin{tabular}{|c|c|c|c|c|c|c|c|c|c|}
\hline Espécies & $\mathrm{N}$ & $\mathrm{P}$ & $\begin{array}{l}\mathrm{AB} \\
\left(\mathrm{m}^{2}\right)\end{array}$ & $\begin{array}{c}\mathrm{D} \\
(\mathrm{cm})\end{array}$ & $\begin{array}{l}\mathrm{H} \\
(\mathrm{m})\end{array}$ & $\begin{array}{c}\text { DA } \\
\text { (I/ha) }\end{array}$ & $\begin{array}{l}\text { FA } \\
(\%)\end{array}$ & $\begin{array}{c}\text { DoA } \\
\left(\mathrm{m}^{2} / \mathrm{ha}\right)\end{array}$ & VI \\
\hline Eremanthus erythropappus & 6 & 1 & 0,070 & 15,4 & 8,0 & 4,7 & 3,13 & 0,055 & 0,56 \\
\hline Protium heptaphyllum & 3 & 3 & 0,037 & 16,2 & 15,0 & 2,3 & 9,38 & 0,029 & 0,56 \\
\hline Callisthene major & 4 & 2 & 0,059 & 24,0 & 12,0 & 3,1 & 6,25 & 0,046 & 0,55 \\
\hline Protium widgrenii & 6 & 2 & 0,023 & 8,3 & 9,0 & 4,7 & 6,25 & 0,018 & 0,54 \\
\hline Maytenus glazioviana & 3 & 3 & 0,017 & 10,8 & 9,0 & 2,3 & 9,38 & 0,013 & 0,51 \\
\hline Zanthoxylum caribaeum & 3 & 3 & 0,020 & 12,4 & 12,0 & 2,3 & 9,38 & 0,015 & 0,51 \\
\hline Maytenus salicifolia & 3 & 3 & 0,016 & 10,0 & 7,0 & 2,3 & 9,38 & 0,012 & 0,50 \\
\hline Schefflera acuminata & 3 & 3 & 0,016 & 10,8 & 13,0 & 2,3 & 9,38 & 0,012 & 0,50 \\
\hline Connarus regnellii & 3 & 3 & 0,011 & 8,3 & 6,5 & 2,3 & 9,38 & 0,009 & 0,49 \\
\hline Byrsonima laxiflora & 5 & 2 & 0,018 & 9,9 & 10,0 & 3,9 & 6,25 & 0,014 & 0,48 \\
\hline Inga ingoides & 1 & 1 & 0,109 & 37,2 & 14,0 & 0,8 & 3,13 & 0,085 & 0,45 \\
\hline Ocotea pulchella & 2 & 2 & 0,052 & 25,2 & 15,5 & 1,6 & 6,25 & 0,041 & 0,45 \\
\hline Psidium cattleyanum & 3 & 2 & 0,030 & 12,8 & 8,5 & 2,3 & 6,25 & 0,024 & 0,43 \\
\hline Ternstroemia brasiliensis & 5 & 1 & 0,039 & 13,6 & 8,5 & 3,9 & 3,13 & 0,030 & 0,43 \\
\hline Nectandra grandiflora & 2 & 1 & 0,080 & 29,6 & 8,0 & 1,6 & 3,13 & 0,063 & 0,42 \\
\hline Siphoneugena densiflora & 3 & 2 & 0,027 & 13,4 & 10,5 & 2,3 & 6,25 & 0,021 & 0,42 \\
\hline Sloanea monosperma & 3 & 2 & 0,025 & 14,7 & 9,0 & 2,3 & 6,25 & 0,019 & 0,42 \\
\hline Acacia recurva & 2 & 1 & 0,074 & 22,3 & 6,0 & 1,6 & 3,13 & 0,058 & 0,40 \\
\hline Nectandra oppositifolia & 2 & 2 & 0,036 & 16,9 & 14,5 & 1,6 & 6,25 & 0,028 & 0,40 \\
\hline Luehea candicans & 2 & 2 & 0,030 & 18,9 & 13,0 & 1,6 & 6,25 & 0,024 & 0,39 \\
\hline Ocotea elegans & 2 & 2 & 0,027 & 13,5 & 11,0 & 1,6 & 6,25 & 0,021 & 0,38 \\
\hline Terminalia glabrescens & 2 & 1 & 0,066 & 28,3 & 12,0 & 1,6 & 3,13 & 0,051 & 0,38 \\
\hline Aegiphila sellowiana & 2 & 2 & 0,023 & 15,0 & 9,0 & 1,6 & 6,25 & 0,018 & 0,37 \\
\hline Cordia trichotoma & 4 & 1 & 0,030 & 14,2 & 13,0 & 3,1 & 3,13 & 0,023 & 0,36 \\
\hline Garcinia gardneriana & 3 & 1 & 0,041 & 21,3 & 9,0 & 2,3 & 3,13 & 0,032 & 0,35 \\
\hline Strychnos brasiliensis & 2 & 2 & 0,015 & 10,9 & 6,0 & 1,6 & 6,25 & 0,011 & 0,35 \\
\hline Ocotea diospyrifolia & 2 & 2 & 0,011 & 9,9 & 11,0 & 1,6 & 6,25 & 0,008 & 0,33 \\
\hline Qualea multiflora & 2 & 2 & 0,009 & 9,4 & 10,0 & 1,6 & 6,25 & 0,007 & 0,33 \\
\hline Randia nitida & 2 & 2 & 0,006 & 6,1 & 6,0 & 1,6 & 6,25 & 0,004 & 0,32 \\
\hline Senna multijuga & 1 & 1 & 0,060 & 27,7 & 13,0 & 0,8 & 3,13 & 0,047 & 0,32 \\
\hline Trichilia pallida & 2 & 2 & 0,004 & 5,4 & 9,0 & 1,6 & 6,25 & 0,003 & 0,32 \\
\hline Ilex conocarpa & 3 & 1 & 0,015 & 9,2 & 9,0 & 2,3 & 3,13 & 0,012 & 0,28 \\
\hline Euplassa incana & 1 & 1 & 0,039 & 22,3 & 10,5 & 0,8 & 3,13 & 0,031 & 0,26 \\
\hline Inga vera & 1 & 1 & 0,040 & 22,4 & 11,0 & 0,8 & 3,13 & 0,031 & 0,26 \\
\hline Matayba juglandifolia & 2 & 1 & 0,016 & 11,3 & 5,0 & 1,6 & 3,13 & 0,013 & 0,24 \\
\hline Calyptranthes brasiliensis & 2 & 1 & 0,010 & 8,8 & 8,0 & 1,6 & 3,13 & 0,008 & 0,22 \\
\hline Trembleya parviflora & 2 & 1 & 0,006 & 6,7 & 4,5 & 1,6 & 3,13 & 0,005 & 0,21 \\
\hline Ilex brevicuspis & 1 & 1 & 0,017 & 14,6 & 10,0 & 0,8 & 3,13 & 0,013 & 0,20 \\
\hline Sapium glandulosum & 1 & 1 & 0,015 & 13,9 & 10,0 & 0,8 & 3,13 & 0,012 & 0,19 \\
\hline Cecropia glaziovii & 1 & 1 & 0,011 & 11,9 & 9,0 & 0,8 & 3,13 & 0,009 & 0,18 \\
\hline Deguelia hatschbachii & 1 & 1 & 0,010 & 11,5 & 11,0 & 0,8 & 3,13 & 0,008 & 0,18 \\
\hline Prunus myrtifolia & 1 & 1 & 0,009 & 10,5 & 8,0 & 0,8 & 3,13 & 0,007 & 0,18 \\
\hline Ocotea indecora & 1 & 1 & 0,005 & 8,3 & 10,5 & 0,8 & 3,13 & 0,004 & 0,17 \\
\hline Cordia superba & 1 & 1 & 0,005 & 8,3 & 11,0 & 0,8 & 3,13 & 0,004 & 0,17 \\
\hline Mollinedia argyrogyna & 1 & 1 & 0,007 & 9,6 & 8,0 & 0,8 & 3,13 & 0,006 & 0,17 \\
\hline Myrcia fallax & 1 & 1 & 0,007 & 9,6 & 12,0 & 0,8 & 3,13 & 0,006 & 0,17 \\
\hline Myrsine coriacea & 1 & 1 & 0,006 & 8,8 & 6,5 & 0,8 & 3,13 & 0,005 & 0,17 \\
\hline Vernonanthura diffusa & 1 & 1 & 0,007 & 9,4 & 9,0 & 0,8 & 3,13 & 0,005 & 0,17 \\
\hline Actinostemon klotzschii & 1 & 1 & 0,004 & 7,3 & 3,0 & 0,8 & 3,13 & 0,003 & 0,16 \\
\hline Calyptranthes clusiifolia & 1 & 1 & 0,002 & 4,9 & 6,0 & 0,8 & 3,13 & 0,002 & 0,16 \\
\hline
\end{tabular}


Tabela 3. (continuação)

\begin{tabular}{lccccccccc}
\hline Espécies & $\mathrm{N}$ & $\mathrm{P}$ & $\begin{array}{c}\mathrm{AB} \\
\left(\mathrm{m}^{2}\right)\end{array}$ & $\begin{array}{c}\mathrm{D} \\
(\mathrm{cm})\end{array}$ & $\begin{array}{c}\mathrm{H} \\
(\mathrm{m})\end{array}$ & $\begin{array}{c}\mathrm{DA} \\
(\mathrm{I} / \mathrm{ha})\end{array}$ & $\begin{array}{c}\mathrm{FA} \\
(\%)\end{array}$ & $\begin{array}{c}\text { DoA } \\
\left(\mathrm{m}^{2} / \mathrm{ha}\right)\end{array}$ & VI \\
\hline Campomanesia velutina & 1 & 1 & 0,004 & 6,7 & 6,0 & 0,8 & 3,13 & 0,003 & 0,16 \\
Celtis iguanaea & 1 & 1 & 0,002 & 5,6 & 6,0 & 0,8 & 3,13 & 0,002 & 0,16 \\
Croton urucurana & 1 & 1 & 0,002 & 4,9 & 6,0 & 0,8 & 3,13 & 0,002 & 0,16 \\
Guapira opposita & 1 & 1 & 0,002 & 4,9 & 4,5 & 0,8 & 3,13 & 0,002 & 0,16 \\
Hirtella hebeclada & 1 & 1 & 0,002 & 5,6 & 7,5 & 0,8 & 3,13 & 0,002 & 0,16 \\
Matayba guianensis & 1 & 1 & 0,004 & 6,7 & 7,0 & 0,8 & 3,13 & 0,003 & 0,16 \\
Miconia pepericarpa & 1 & 1 & 0,003 & 6,2 & 3,0 & 0,8 & 3,13 & 0,002 & 0,16 \\
Miconia trianae & 1 & 1 & 0,004 & 7,0 & 8,0 & 0,8 & 3,13 & 0,003 & 0,16 \\
Ocotea odorifera & 1 & 1 & 0,002 & 4,9 & 4,0 & 0,8 & 3,13 & 0,002 & 0,16 \\
Prunus sellowii & 1 & 1 & 0,004 & 7,0 & 7,5 & 0,8 & 3,13 & 0,003 & 0,16 \\
Rhamnus sphaerosperma & 1 & 1 & 0,004 & 7,3 & 8,0 & 0,8 & 3,13 & 0,003 & 0,16 \\
Sebastiania commersoniana & 1 & 1 & 0,002 & 4,9 & 4,5 & 0,8 & 3,13 & 0,002 & 0,16 \\
Xylopia brasiliensis & 1 & 1 & 0,003 & 5,7 & 5,0 & 0,8 & 3,13 & 0,002 & 0,16 \\
Zanthoxylum rhoifolium & 1 & 1 & 0,002 & 5,4 & 8,5 & 0,8 & 3,13 & 0,002 & 0,16 \\
& & & & & & & & &
\end{tabular}

em alguns locais e menos abundante em outros.

Outras espécies com densidade variável e distribuição ampla são Tapirira guianensis, T. obtusa, Croton floribundus, Piptadenia gonoacantha, Matayba elaeagnoides, Cabralea canjerana, Ceiba speciosa e Mollinedia widgrenii (Durigan et al. 2000). É interessante destacar que, na Mata do Galego, T. guianensis apresentou 15 indivíduos em uma das parcelas da margem do rio e, nas outras quatorze parcelas em que foi amostrada, apresentou quatro ou menos indivíduos em cada. Talvez a luminosidade seja a principal variável relacionada à distribuição dessa espécie na área de estudo, pois, segundo Oliveira Filho \& Ratter (2000), ela ocorre geralmente em clareiras e bordas de matas ciliares e também em formações vegetais mais abertas, como o cerrado.

As espécies Cedrela fissilis, Maclura tinctoria, Cariniana estrellensis, Campomanesia xanthocarpa, Cordia superba e Annona cacans geralmente apresentam baixa densidade e ampla distribuição. Entretanto, alterações antrópicas no ambiente levam a aumento na densidade dessas espécies (Durigan et al. 2000). Na Mata do Galego, entre essas espécies, $C$. fissilis e $M$. tinctoria apresentaram os maiores valores de densidade absoluta $(10,9)$, o que pode estar refletindo o histórico de perturbação da área.

Entre as 159 espécies amostradas na Mata do Galego, 31 só tiveram um indivíduo, representando 19,5\% das espécies. Algumas vezes, o conceito de espécie rara tem sido usado para indicar as espécies que ocorrem com baixa densidade populacional em levantamentos estruturais. No entanto, essas espécies podem não ser realmente raras, mas sim apresentarem apenas baixa densidade populacional, devido a alguns fatores relacionados aos procedimentos no levantamento ou às características das espécies. Entre esses fatores estão o tamanho da área amostral, as restrições estabelecidas nos levantamentos estruturais e o padrão de distribuição e estádios sucessionais das espécies (Durigan et al. 2000).

Em ecossistemas não perturbados, as espécies podem ser divididas em três grupos, de acordo com sua densidade, sendo consideradas raras aquelas que apresentam menos de um indivíduo por hectare; intermediárias aquelas com um indivíduo por hectare; ou comuns, espécies com mais de um 
indivíduo por hectare (Kageyama \& Gandara 2000). Entre esses grupos, as espécies comuns seriam as mais adequadas para manejo racional, enquanto as espécies raras seriam adequadas como indicadores para tamanho de reserva genética, servindo, assim, como referência nas estratégias de conservação (Kageyama \& Gandara 1994).

A abundância relativa das espécies e a riqueza florística se refletem no valor do índice de diversidade do local. A Mata do Galego apresentou alta diversidade $\left(\mathrm{H}^{\prime}=4,23\right.$ nat/indivíduo) e alta equabilidade $\left(\mathrm{J}^{\prime}=0,83\right)$. Valores de diversidade semelhantes foram obtidos em outros estudos da região, como o de Oliveira Filho et al. (1994a) na mata ciliar da Reserva Biológica de Poço Bonito (Lavras, MG), que apresentou H' = 4,204 nat/ indivíduo e J' = 0,88; e o de Carvalho et al. (1995b) em mata ripária em Bom Sucesso (MG), com $\mathrm{H}^{\prime}=4,331$ nat/indivíduo e J' $=0,857$. Já estudos realizados em matas semidecíduas montanas apresentaram índices de diversidade inferiores ao da Mata do Galego, como, por exemplo, o levantamento estrutural realizado em uma floresta em Itutinga (MG), que obteve $\mathrm{H}^{\prime}=3,89$ e J' = 0,75 (Vilela et al. 1994); e o estudo realizado na reserva da Universidade Federal de Lavras, com $\mathrm{H}^{\prime}=3,605$ e J' = 0,734 (Oliveira Filho et al. 1994b). No entanto, é preciso ressaltar que nos trabalhos comparados acima, o método utilizado nos levantamentos estruturais e a área amostral foram diferentes do presente trabalho.

O índice de diversidade de famílias foi $\mathrm{H}^{\prime}=3,15$ nat/indivíduo. As famílias com maior riqueza florística foram Myrtaceae (15), Lauraceae (13), Rubiaceae (nove), Fabaceae Faboideae (nove), Fabaceae Mimosoideae (oito), Malvaceae (oito) Euphorbiaceae (sete), Annonaceae (seis) e Rutaceae (cinco). Essas famílias são geralmente bem representadas em levantamentos estruturais da região, como mostrado em uma comparação feita por Carvalho et al. (1996), e também em matas semidecíduas do Estado de São Paulo (Rodrigues et al. 1989; Cesar \& Leitão Filho 1990).
Ocorreram 20 famílias representadas por apenas uma espécie e, destas, cinco apresentaram apenas um indivíduo. As famílias com os maiores números de indivíduos foram Fabaceae Faboideae (284), Anacardiaceae (236), Flacourtiaceae (223), Rubiaceae (194), Fabaceae Caesalpinioideae (134), Lauraceae (126), Myrtaceae (117), Euphorbiaceae (99), Ebenaceae (91) e Annonaceae (89). Juntas, estas famílias representam $67,99 \%$ dos indivíduos amostrados. Essas famílias também apresentaram os maiores valores de VI. Interessante é que as famílias Ebenaceae e Anacardiaceae apresentaram grande número de indivíduos de apenas uma e três espécies, respectivamente. Essa última família superou o número de indivíduos inclusive das famílias que apresentaram os maiores números de espécies, Myrtaceae e Lauraceae.

A diversidade de espécies e famílias pode estar relacionada à influência de formações vegetais próximas e aos diferentes microhabitats presentes na Mata do Galego, proporcionados por clareiras, topografia, pela variação de fertilidade do solo das parcelas e também pela presença de um curso d'água. Geralmente, as faixas de vegetação ciliar apresentam grande heterogeneidade ambiental, em conseqüência de fatores bióticos e abióticos, que resultam em manchas de vegetação com diferentes características florísticas e estruturais (Rodrigues 2000). Alguns estudos têm mostrado que as áreas de amostragem que se encontram fora da influência de cursos d'água apresentam diferenças conspícuas daquelas diretamente influenciadas pelos mesmos (Metzger et al. 1997).

$\mathrm{Na}$ parte da Mata do Galego que foi estudada parece não ocorrerem inundações com freqüência, devido ao relevo da área. Como conseqüência, não foram encontradas, nas parcelas da margem, espécies como Protium spruceanum, Calophyllum brasiliense, Croton urucurana, Endlicheria paniculata e Hyeronima ferruginea, que foram amostradas 
no levantamento florístico e que, segundo Oliveira Filho \& Fluminhan Filho (1999), estão associadas à condição ripária.

Pode-se concluir que a flora da Mata do Galego apresenta espécies representantes do cerrado, campos rupestres, matas estacionais semidecíduas e matas ciliares. A diversidade florística é alta, resultado, provavelmente, da interação com áreas adjacentes e da heterogeneidade ambiental, provocada pela topografia e pelas variações nas características químicas e físicas do solo.

\section{Agradecimentos}

Os autores agradecem ao Prof. Dr. Nilton Curi pela identificação dos solos, aos alunos do Departamento de Engenharia Florestal da UFLA - em particular Edmilson Santos Cruz, Lucas Gomide e Lucas Guida - a Marco Aurélio Fontes (docente) e José Carlos (funcionário), pelo auxílio nos trabalhos de campo; aos proprietários das Fazendas Barreiro e Morro Grande, por permitirem a realização deste trabalho na Mata do Galego; ao PROBIO pelo apoio financeiro.

\section{Referências bibliográficas}

Carvalho, D. A.; Oliveira Filho, A. T. \& Vilela, E. A. 1996. Flora arbustivo-arbórea de mata ripária do médio Rio Grande (Conquista, Estado de Minas Gerais). Cerne 2(2): 48-68.

Carvalho, D. A.; Oliveira Filho, A. T.; Vilela, E. A. \& Curi, N. 2000. Florística e estrutura da vegetação arbórea de um fragmento de floresta semidecidual às margens do reservatório da usina hidrelétrica dona Rita (Itambé do Mato Dentro, MG). Acta Botanica Brasilica 14(1): 37-55.

Carvalho, D. A.; Oliveira Filho, A. T.; Vilela, E. A. \& Gavilanes, M. L. 1995a. Flora arbustivo-arbórea de uma floresta ripária no alto rio Grande em Bom Sucesso/MG. Acta Botanica Brasilica 9(2): 231-245.

Carvalho, D. A.; Oliveira Filho, A. T.; Vilela, E. A. \& Gavilanes, M.L. 1995b. Estrutura fitossociológica de mata ripária do alto Rio Grande (Bom Sucesso, Estado de Minas Gerais). Revista Brasileira de Botânica 18(1): 39-49.
Cesar, O. \& Leitão Filho, H. F. 1990. Estudo florístico quantitativo de mata mesófila semidecídua na Fazenda Barreiro Rico, Município de Anhembi, São Paulo. Revista Brasileira de Biologia 50: 133-147.

Corrêa, M. P. 1975. Dicionário das plantas úteis do Brasil e das exóticas cultivadas. IBDF, Rio de Janeiro. V I-VI.

Cronquist, A. 1981. An integral system of classification of flowering plants. Columbia University Press, New York.

Durigan, G.; Rodrigues, R. R. \& Schiavini, I. 2000. A heterogeneidade ambiental definindo a metodologia de amostragem da floresta ciliar. Pp. 159-167. In: Rodrigues, R.R. \& Leitão Filho, H.F. (eds.). Matas ciliares: conservação e recuperação. EDUSP, São Paulo.

Empresa Brasileira de Pesquisa Agropecuária. Serviço Nacional de Levantamento e Conservação de Solos. 1979. Manual de método de análises de solos. EMBRAPA, Rio de Janeiro.

Empresa Brasileira de Pesquisa Agropecuária. Centro Nacional de Pesquisa de Solos. 1999. Sistema Brasileiro de Classificação de Solos. EMBRAPA, Brasília.

Felfili, J. M. 1998. Determinação de padrões de distribuição de espécies em uma mata de galeria no Brasil Central com a utilização de técnicas de análise multivariada. Boletim do Herbário Ezechias Paulo Heringer 2: 35-47.

Gandolfi, S.; Leitão Filho, H. F. \& Bezerra, C. L. F. 1995. Levantamento florístico e caráter sucessional das espécies arbustivo-arbóreas de uma floresta mesófila semidecídua no Município de Guarulhos, SP. Revista Brasileira de Biologia 55(4): 753-767.

Judd, W. S.; Campbell, C. S.; Kellog, E. A. \& Stevens, P. F. 1999. Plant systematics: a phylogenetic approach. Sinauer Associsates, Massachusetts.

Kageyama, P. Y. \& Gandara, F. B. 1994. Dinâmica de populações de espécies arbóreas: implicações para o manejo e a conservação. Pp. 115-125. In: Anais do III Simpósio de Ecossistemas da Costa Brasileira. Serra Negra. 1993. Academia de Ciências do Estado de São Paulo, São Pulo.

Kageyama, P. \& Gandara, F. B. 2000. Recuperação de áreas ciliares. Pp. 249-269. In: Rodrigues, R. R. \& Leitão Filho, H. F. (eds.). Matas ciliares: conservação e recuperação. EDUSP, São Paulo.

Ledru, M. P. 1993. Late quaternary environmental and climate changes in Central Brazil. Quaternary Research 39: 90-98.

Lorenzi, H. 1992. Árvores brasileiras: manual de identificação e cultivo de plantas arbóreas nativas do Brasil. Plantarum, Nova Odessa. 
Magurran, A. 1988. Ecological diversity and measurement. Princeton University Press, Princeton.

Metzger, J. P.; Bernacci, L. C. \& Goldenberg, R. 1997. Pattern of tree species diversity in riparian forest fragments of different widths (SE Brazil). Plant Ecology 133: 135-152.

Mueller-Dombois, D. \& Ellenberg, H. 1974. Aims and methods of vegetation ecology. Wiley and Sons, New York.

Oliveira Filho, A. T.; Almeida, R. J.; Mello, J. M. \& Gavilanes, M. L. 1994a. Estrutura fitossociológica e variáveis ambientais em um trecho de mata ciliar do córrego Vilas Boas, Reserva Biológica do Poço Bonito, Lavras (MG). Revista Brasileira de Botânica 17(1): 67-85.

Oliveira Filho, A. T.; Curi, N.; Vilela, E. A. \& Carvalho, D. A. 1998. Effects of canopy gaps, topography, and soils on the distribution of woody species in a Central Brazilian Deciduous Dry Forest. Biotropica 30(3): 362-375.

Oliveira Filho, A. T. \& Fluminhan Filho, M. 1999. Ecologia da vegetação do Parque Florestal Quedas do Rio Bonito. Cerne 5(2): 51-64.

Oliveira Filho, A. T. \& Ratter, J. A. 2000. Padrões florísticos das matas ciliares da região do Cerrado e a evolução das paisagens do Brasil Central durante o Quaternário Tardio. Pp. 73-89. In: Rodrigues, R.R. \& Leitão Filho, H.F. (eds.). Matas ciliares: conservação e recuperação. EDUSP, São Paulo.

Oliveira Filho, A. T.; Scolforo, J. R. \& Mello, J. M. 1994b. Composição florística e estrutura comunitária de um remanescente de floresta semidecídua montana em Lavras, MG. Revista Brasileira de Botânica 17(2): 167-182.

Oliveira Filho; A. T.; Vilela, E. A.; Carvalho, D. A. \& Gavilanes, M. L. 1994c. Differentiation of streamside and upland vegetation in area of montane semideciduous forest in south-eastern Brazil. Flora 189: 287-305.

Oliveira Filho; A. T.; Vilela, E. A.; Carvalho, D. A. \& Gavilanes, M. L. 1994d. Effects of soils and topography on the distribution of tree species in a tropical riverine forest in south-eastern Brazil. Journal of Tropical Ecology 10: 483-508.

Oliveira Filho. A. T.; Vilela, E. A.; Gavilanes, M. L. \& Carvalho, D. A. 1994e. Comparison of the woody flora and soils of six areas of montane semideciduous forest in southern Minas Gerais, Brazil. Edinburgh Journal of Botany 51(3): 355-389.

Pagano, S. N. \& Leitão Filho, H. F. 1987. Composição florística do estrato arbóreo de mata mesófila semidecídua, no Município de Rio Claro (Estado de São Paulo). Revista Brasileira de Botânica 10: 37-47.
Prado, D. E. \& Gibbs, P. E. 1993. Patterns of species distributions in the Dry Seasonal Forests of South America. Annals of the Missouri Botanical Garden 80: 902-927.

Ratter, J. A.; Askew, G. P.; Montgomery, R. F. \& Gifford, D. R. 1978. Observations on forests of some mesotrophic soils in Central Brazil. Revista Brasileira de Botânica 1: 47-58.

Rodrigues, L. A. \& Araújo, G. M. 1997. Levantamento florístico de uma mata decídua em Uberlândia, Minas Gerais, Brasil. Acta Botanica Brasilica 11(2): 229-236.

Rodrigues, R. R. 2000. Uma discussão nomenclatural das formações ciliares. Pp. 91-99. In: Rodrigues, R.R. \& Leitão Filho, H.F. (eds.). Matas ciliares: conservação e recuperação. EDUSP, São Paulo.

Rodrigues, R. R.; Morellato, L. P. C.; Joly, C. A. \& Leitão Filho, H. F. 1989. Estudo florístico e fitossociológico em um gradiente altitudinal de mata estacional mesófila semidecídua, na Serra do Japi, Jundiaí, SP. Revista Brasileira de Botânica 12: 71-84.

Rodrigues, R. R. \& Nave, A. G. 2000. Heterogeneidade florística das matas ciliares. Pp. 45-71. In: Rodrigues, R. R. \& Leitão Filho, H. F. (eds.). Matas ciliares: conservação e recuperação. EDUSP, São Paulo.

Rossi, C. V.; Silva Júnior, M. C. \& Santos, C. E. N. 1998. Fitossociologia do estrato arbóreo do cerrado (sensu stricto) no Parque Ecológico Norte, Brasília - DF. Boletim do Herbário Ezechias Paulo Heringer 2: 49-56.

Sampaio, A. B.; Nunes, R. V. \& Walter, B. M. T. 1997. Fitossociologia de uma mata de galeria na Fazenda Sucupira do Cenargen, Brasília/DF. Pp. 29-37. In: Leite, L.L. \& Saito, C.H. (eds.). Contribuição ao conhecimento ecológico do Cerrado. UnB, Brasília.

Scolforo, J. R. S. \& Mello, J. M. 1997. Inventário florestal. UFLA/FAEPE, Lavras.

Shepherd, G.J. 1994. FITOPAC 1: manual do usuário. UNICAMP, Campinas.

Veloso, H. P.; Rangel Filho, A. L. R. \& Lima, J. C. A. 1991. Classificação da vegetação brasileira adaptada a um sistema universal. IBGE, Rio de Janeiro.

Vilela, E. A.; Oliveira Filho, A. T.; Carvalho, D. A. \& Gavilanes, M. L. 1994. Fitossociologia e fisionomia de mata semidecídua margeando o reservatório de Camargos em Itutinga, Minas Gerais. Ciência e Prática 18(4): 415-424.

Vilela, E. A.; Oliveira Filho, A. T.; Carvalho, D. A. \& Gavilanes, M. L. 1995. Flora arbustivo-arbórea de um fragmento de mata ciliar no alto rio Grande, Itutinga, Minas Gerais. Acta Botanica Brasilica 9(1): 87-100. 